\title{
Specific humoral and cellular immunity induced by Trypanosoma cruzi DNA immunization in a canine model
}

\author{
Minerva Arce-Fonseca', Martha A Ballinas-Verdugo ${ }^{1}$, Emma R Abreu Zenteno ${ }^{1}$, Davinia Suárez-Flores ${ }^{1}$, \\ Silvia C Carrillo-Sánchez ${ }^{1}$, Ricardo Alejandre-Aguilar², José Luis Rosales-Encina ${ }^{3}$, Pedro A Reyes ${ }^{4}$ and \\ Olivia Rodríguez-Morales ${ }^{1 *}$
}

\begin{abstract}
Chagas disease has a high incidence in Mexico and other Latin American countries. Because one of the most important known methods of prevention is vector control, which has been effective only in certain areas of South America, the development of a vaccine to protect people at risk has been proposed. In this study, we assessed the cellular and humoral immune response generated following immunization with pBCSP and pBCSSP4 plasmids containing the genes encoding a trans-sialidase protein (present in all three forms of $T$. cruzi) and an amastigote specific glycoprotein, respectively, in a canine model. Thirty-five beagle dogs were divided randomly into 5 groups $(n=7)$ and were immunized twice intramuscularly with $500 \mu \mathrm{g}$ of pBCSSP4, pBCSP, pBk-CMV (empty plasmid) or saline solution. Fifteen days after the last immunization the 4 groups were infected intraperitoneally with 500000 metacyclic trypomastigotes. The fifth group was unimmunized/infected. The parasitaemia in the immunized/ infected dogs was for a shorter period (14 vs. 29 days) and the parasite load was lower. The concentration of IgG1 $(0.612 \pm 0.019$ O.D.) and lgG2 (1.167 \pm 0.097 O.D.) subclasses was measured (absorbance) 15 days after the last immunization with both recombinant plasmids, the majority of which were $\operatorname{lgG} 2$. The treatment of parasites using the serum from dogs immunized with pBCSP and pBCSSP4 plasmids produced 54\% ( \pm 11.8$)$ and $68 \%( \pm 21.4)$ complement-mediated lysis, respectively. At $12 \mathrm{~h}$ post immunization, an increase in cytokines was not observed; however, vaccination with PBCSSP4 significantly increased the levels of IFN- $\gamma$ and IL-10 at 9 months post-infection. The recombinant plasmid immunization stimulated the spleen cell proliferation showing a positive stimulatory index above 2.0. In conclusion, immunization using both genes effectively induces a humoral and cellular immune response.
\end{abstract}

\section{Introduction}

Chagas' disease, caused by the parasite protozoan Trypanosoma cruzi, is estimated to affect 10 million people in the Americas [1]. To date, the most important prevention method is to campaign for the elimination of the vector; however, these efforts have achieved only partial control of the disease. There is a need for an immunoprotective vaccine to decrease the morbidity and mortality caused by this parasitic disease. Many attempts

\footnotetext{
* Correspondence: rm.olivia@gmail.com

'Department of Molecular Biology, Instituto Nacional de Cardiología "Ignacio Chávez", Juan Badiano No. 1, Col. Sección XVI, Tlalpan, CP 14080, Mexico City, Mexico

Full list of author information is available at the end of the article
}

have been made to generate a vaccine using the $T$. cruzi highly immunogenic surface antigens, recombinant antigens, and recently, the administration of test plasmid DNA encoding different genes has been investigated. The results of these tests have varied from no protection against the disease to the partial reduction of short-term mortality and morbidity rates in a murine model [2-4]. Although there have been a number of successes using this type of vaccine, it is necessary to improve the vaccinemediated immune response, to document the results in detail, and to replicate the experiments in other species. The canine model is ideal because dogs develop the signs of the disease and immunopathological changes that are similar in humans; in addition, dogs are considered
C Biomed Central 
important domestic reservoirs of the parasite and contribute to the transmission of $T$. cruzi to humans; therefore, a decrease in the incidence of the disease in this species would have significant beneficial effects for humans [5-7].

In the case of Chagas disease, the cell-type immune response plays a fundamental role because the parasite exhibits an intracellular phase during the infection. One of the best indicators of the establishment of a cellular immune response is the production of type 1 cytokines, whereas type 2 cytokines promote the antibody response.

It has been established that the predominance of Th1 cytokines is more effective in eliminating the parasite and therefore, reduces parasitaemia during the acute phase. In the later stages of the disease, Th1/Th2 cytokines are associated with the absence of symptoms and the apparent integrity of the cardiac tissue $[8,9]$. Both cellular and humoral immune responses are driven by $\mathrm{CD} 4+\mathrm{T}$ lymphocytes (Th1 and Th2) through signals generated by cytokines. In a previous study, a cDNA clone encoding the amastigote-specific surface protein TcSSP4 was used as a candidate gene to develop a DNA vaccine. The mice were immunized with the recombinant protein $r T c S S P 4$ and with the TcSSP4 cDNA and were challenged with the introduction of blood trypomastigotes. The immunization with the $r T c S S P 4$ protein rendered the mice more susceptible to trypomastigote infection and exhibited high mortality rates, whereas the mice immunized with a eukaryotic expression plasmid containing the TcSSP4 cDNA controlled the acute phase of the infection. Compared with the control animals, the heart tissue of the DNA-vaccinated animals did not demonstrate myocarditis and tissue damage at 365 days following infection. Interferon-gamma (IFN- $\gamma$ ) was detected in the sera of the DNA-vaccinated mice shortly after immunization, suggesting the development of a Th1 response. Therefore, the TcSSP4 gene is a promising candidate for the development of an anti-T. cruzi DNA vaccine [10].

In this study, the humoral and cellular immune responses were evaluated in dogs immunized with $2 \mathrm{~T}$. cruzi genes, TcSP (gene encoding a member of the transsialidase family that is present in all three forms of T. cruzi) [11] and TcSSP4, through the measurement of antibodies and cytokines in the serum, antibody-dependent cell lysis, and the in vitro proliferation of the dog splenocytes.

\section{Materials and methods}

\section{Animals}

Male and female 4-month-old Beagle dogs (35 in total) were purchased from Criadero El Atorón (Teotihuacán, Estado de México; Mexico). All animals were subjected to a physical examination and were quarantined. The dogs were dewormed and vaccinated against the main canine infectious diseases. The dogs were tested for the absence of antibodies against $T$. cruzi using the (ELISA).
The animals were handled in accordance with the guidelines established by international authorities and the Norma Oficial Mexicana technical specifications for the care and use of laboratory animals [12]. The Bioethics Committee of the Instituto Nacional de Cardiología, Ignacio Chávez approved the experimental protocol.

\section{Immunization and challenge}

The dogs were divided randomly into 5 groups $(n=7)$. The groups were immunized with pBCSSP4, pBCSP, pBk-CMV (empty plasmid) or saline solution (SS) (used as a control), and 15 days after the last immunization, the 4 groups were infected with the parasite. The two plasmid constructs (pBCSSP4 and pBCSP) were generated and characterized as described previously [11]. The immunizations consisted of 2 intramuscular injections of $500 \mu \mathrm{g}$ of DNA dissolved in $500 \mu \mathrm{L}$ of SS administered at 2-week intervals.

The parasites were obtained from urine and feces of triatomes and resuspended in physiologic solution. The animals in the fifth group were administered 500000 metacyclic trypomastigotes intraperitoneally. All the animals survived the treatment and they are currently being used in other studies. The challenge was performed using the Ninoa strain of T. cruzi that was isolated from a patient in Mexico [13] and was maintained by serial passages in triatomines.

\section{Parasitaemia}

The parasitaemia was determined microscopically by examining freshly isolated blood samples collected from the brachiocephalic vein of the infected animals every third day, starting on day 10 post-infection until day 65 post-infection.

\section{T. cruzi anti-IgG determination using enzyme-linked immunosorbent assay (ELISA)}

A standardized ELISA to detect the anti T. cruzi antibody using as the antigen a total extraction of $T$. cruzi INC-9 isolate of epimastigote forms [14] was performed to rule out any previous natural infections in all dogs, to establish the production of antibodies following immunization in immunized/non-infected dogs, and to confirm the experimental infection two months after challenge in all infected/unimmunized dogs.

\section{Indirect immunofluorescence (IIF) assay}

The ELISA-reactive sera were processed by IIF using the method described as follows: INC-9 T. cruzi epimastigote suspension was placed on a slide and fixed. A 1:40 dilution of the test serum was made in $1 \mathrm{X}$ phosphate buffered saline (PBS), incubated in a humidified chamber at room temperature for $1 \mathrm{~h}$, and washed under stirring in PBS three times (5 $\mathrm{min}$ for each wash). The slides 
were covered with an optimized dilution (1:100) of fluorescein isothiocyanate- labeled goat anti-dog IgG conjugate (Novus Biologicals). The slides were examined with a UV epifluorescence microscope at 3200 and 3400 magnification for specific trypanosomal fluorescence. Positive fluorescence was defined as detection of green fluorescence on parasites and was labeled with $+1++++$ according to the fluorescence degree watched, using a positive control as the reference point [14].

\section{Complement-mediated lysis assay}

The metacyclic trypomastigotes were obtained from the urine and feces of triatomines and were resuspended in SS; $2 \times 10^{4}$ parasites were incubated with $5 \mu \mathrm{L}$ healthy dog sera or test serum (immunized/non-infected dogs) for $1 \mathrm{~h}$ at $37^{\circ} \mathrm{C}$. Guinea pig complement $(25 \mu \mathrm{L})$ (Faculty of Veterinary Medicine, Universidad Nacional Autónoma de México) was added, and the tubes were incubated for $2 \mathrm{~h}$ at $37^{\circ} \mathrm{C}$. The control tubes contained parasites incubated with test serum and heat-inactivated complement $\left(56^{\circ} \mathrm{C}\right.$ for $\left.30 \mathrm{~min}\right)$, and parasites incubated with pre immune serum and complement. The samples were assayed in triplicate, and the number of motile trypomastigotes was determined using a hemocytometer. The percentage of antibody-dependent cell lysis was calculated by determining the percent killing $=100-[$ (number of parasites after incubation with guinea pig complement/number of parasites after treatment with heat-inactivated complement) $\times 100$ ], as previously reported [15].

\section{Cytokine analysis}

The cytokine levels in the sera of immunized dogs at 12 and $24 \mathrm{~h}$ after the last immunization, or 9 months after the infection, were measured using ELISA. The ELISA for IFN- $\gamma$, interleukin-10 (IL-10) and tumor necrosis factor-alpha (TNF- $\alpha$ ) were performed in accordance with the manufacturer's instructions (Preprotech, Rocky Hill, NJ, USA).

\section{Cell proliferation assay}

On day 15 after the last DNA immunization or SS inoculation, and before the challenge, a partial splenectomy was performed [16]. The canine spleen cells were washed 3 times in Hank's solution (Sigma Aldrich, St. Louis, MO, USA) and were resuspended in Dulbecco's Modified Eagle Medium (DMEM, Gibco BRL) supplemented with $2 \mathrm{mM}$ L-glutamine, $50 \mu \mathrm{M} \beta$-Mercaptoethanol, $1 \%$ (vol/vol) non-essential amino acid solution and $10 \%$ fetal bovine serum, to a concentration of $4 \times 10^{5}$ cells $/ \mathrm{mL}$. The assay was performed in 96-well flat bottom plates (Corning); $100 \mu \mathrm{L}$ of the cell suspension was placed into each well, and the total parasite extract of epimastigote forms was added to a concentration of $10 \mu \mathrm{g} / \mathrm{mL}$. Concanavalin A (Con A) (Sigma Aldrich, St. Louis, MO, USA) was added to a concentration of $2 \mu \mathrm{g} / \mathrm{mL}$ as a positive control. Each determination was performed in duplicate. The cultures were incubated at $37^{\circ} \mathrm{C}$ in $5 \% \mathrm{CO}_{2}$ for $120 \mathrm{~h}$ (or $72 \mathrm{~h}$ for Con A). At $16 \mathrm{~h}$ prior to the end of the incubation, $0.5 \mu \mathrm{Ci}$ of $\left[{ }^{3} \mathrm{H}\right.$ ]-thymidine (Amersham) were added to each well. The lymphocytes were collected using a manual cell harvester, and the amount of incorporated radioactive thymidine was measured using liquid scintillation spectroscopy (Beckman, LS 5801). The stimulation of a specific cellular immune response is represented by the stimulatory index (S.I.) [17].

\section{Statistical analysis}

All the data were analyzed using one-way ANOVA statistics followed by Tukey's analysis. In all cases, differences were considered significant when $P<0.05$.

\section{Results}

Parasitaemia and establishment of infection

All of the experimental animals tested negative in the ELISA prior to the start of the experiment.

All unimmunized/infected dogs exhibited parasitaemia starting on day 22 and lasting until day 51 post-infection, whereas the parasitaemia in the immunized/infected dogs was for a shorter period, from day 32 to 46 postinfection (Table 1). Parasitaemia was too low to be quantified, and parasites were only seen by direct observation. The limit of detection was 200 to 400 parasites/ $\mathrm{mL}$ of blood sample intermittently throughout all analysis. At two months post-inoculation, the T. cruzi infection was diagnosed by the ELISA method and was confirmed by IIF in all unimmunized/infected dogs (data not shown). All animals survived the infection with the parasite, because the strain used is not lethal. However, these dogs showed cardiopathy demonstrated in electrocardiographic studies such as left ventricle enlargement, intraventricular conduction defects, right bundle branch block and ventricular premature complexes. In immunized/infected dogs, the quality and quantity of the electrocardiographic abnormalities diminished [11].

\section{Humoral immune response}

Determination of the parasite-specific immunoglobulin G (IgG) antibodies using ELISA revealed that immunization with both recombinant plasmids induced a significant production of $\operatorname{IgG}$ against the parasite 15 days after the last immunization (immunized/non-infected dog determination of the parasite-specific immunoglobulin G (IgG) antibodies using ELISA revealed that immunization with both recombinant plasmids induced a significant production of IgG against the parasite 15 days after the last immunization (immunized/non-infected dogs). As shown in Figure 1B, ELISA analysis shows that recombinant plasmid immunized/non-infected dogs displayed T. cruzi-specific IgG1 
Table 1 Parasitemia detection in DNA-immunized dogs with experimental T. cruzi infection

\begin{tabular}{|c|c|c|c|c|c|c|c|c|c|c|c|}
\hline \multirow[t]{2}{*}{ Group } & \multirow[t]{2}{*}{ Dog } & \multicolumn{10}{|c|}{ Days after inoculation } \\
\hline & & $10-15$ & $16-20$ & $21-25$ & $26-30$ & $31-35$ & $36-40$ & $41-45$ & $46-50$ & $51-60$ & 6165 \\
\hline \multirow[t]{6}{*}{$\mathrm{pBCSP}$} & 1 & & & & & & & + & + & & \\
\hline & 2 & & & & & + & & & & & \\
\hline & 3 & & & & & & & & & & \\
\hline & 4 & & & & & & & & & & \\
\hline & 5 & & & & & & & & & & \\
\hline & 6 & & & & & & & & & & \\
\hline \multirow[t]{6}{*}{ pBCSSP4 } & 1 & & & & & & + & & & & \\
\hline & 2 & & & & & & + & & & & \\
\hline & 3 & & & & & & & & & & \\
\hline & 4 & & & & & & & & & & \\
\hline & 5 & & & & & & & & & & \\
\hline & 6 & & & & & & & & & & \\
\hline \multirow[t]{6}{*}{ pBk-CMV } & 1 & & & & & + & + & & & & \\
\hline & 2 & & & & & + & + & + & & & \\
\hline & 3 & & & & & + & + & & & & \\
\hline & 4 & & & & & & & & & & \\
\hline & 5 & & & & & & & & & & \\
\hline & 6 & & & & & & & & & & \\
\hline \multirow[t]{6}{*}{ SS mock-immunized } & 1 & & & & & & ++ & ++ & & + & \\
\hline & 2 & & & & & & ++ & & & & \\
\hline & 3 & & & & & & ++ & ++ & + & + & \\
\hline & 4 & & & & & + & & & & + & \\
\hline & 5 & & & ++ & ++ & & ++ & & & & \\
\hline & 6 & & & + & ++ & & ++ & & & & \\
\hline
\end{tabular}

+ Detection of 1 or 2 parasites per blood sample of fresh drop examination.

subclass levels significantly higher with respect to SSinoculated/non-infected and pBk-CMV-immunized/noninfected dogs.

The DNA immunization with recombinant plasmids induced a predominant Th1 type antibody response because of the IgG produced, the majority belonging to the IgG2 subclass and to a lesser extent, to the IgG1 subclass (Figure 1C).

As expected, all dogs exhibited high levels of antibodies against T. cruzi after challenge (Figure 1).

\section{Complement-mediated lysis}

To assess the biological activities of the antibodies induced by the DNA immunization, we performed complementmediated parasite lysis assays. The sera of dogs immunized with the recombinant plasmids were in contact with the metacyclic trypomastigotes and guinea pig complement. The antibodies produced by the dogs immunized with the recombinant plasmids induced the complementmediated lysis of trypomastigotes in vitro. The specific lysis of parasites was not detected when the pre immune serum or the serum from dogs immunized with the control empty plasmid or SS were used.

Treating the parasites with the serum from the dogs immunized with pBCSSP4 or pBCSP plasmids resulted in $68 \%( \pm 21.4)$ and $54 \%( \pm 11.8)$ lysis, respectively (Figure 2); the results with both plasmids were similar.

\section{Cytokine quantification}

The DNA vaccines tested did not generate increased cytokines at $12 \mathrm{~h}$ post immunization; however, at 9 months post-infection, although both DNA vaccines were tested, only the pBCSSP4 plasmid induced a significant increase in IFN- $\gamma(1080 \mathrm{pg} / \mathrm{mL} \pm 100)$ and IL-10 $(800 \mathrm{pg} / \mathrm{mL} \pm$ 102) levels in the dogs (Figure 3 ) at this same time, the values obtained with the pBCSP plasmid-immunization for IFN- $\gamma(100 \mathrm{pg} / \mathrm{mL} \pm 20)$, IL-10 (102 pg/mL \pm 68), and TNF- $\alpha(221 \mathrm{pg} / \mathrm{mL} \pm 15)$ were similar to those observed at the different experimental conditions analyzed (Figure 3). 

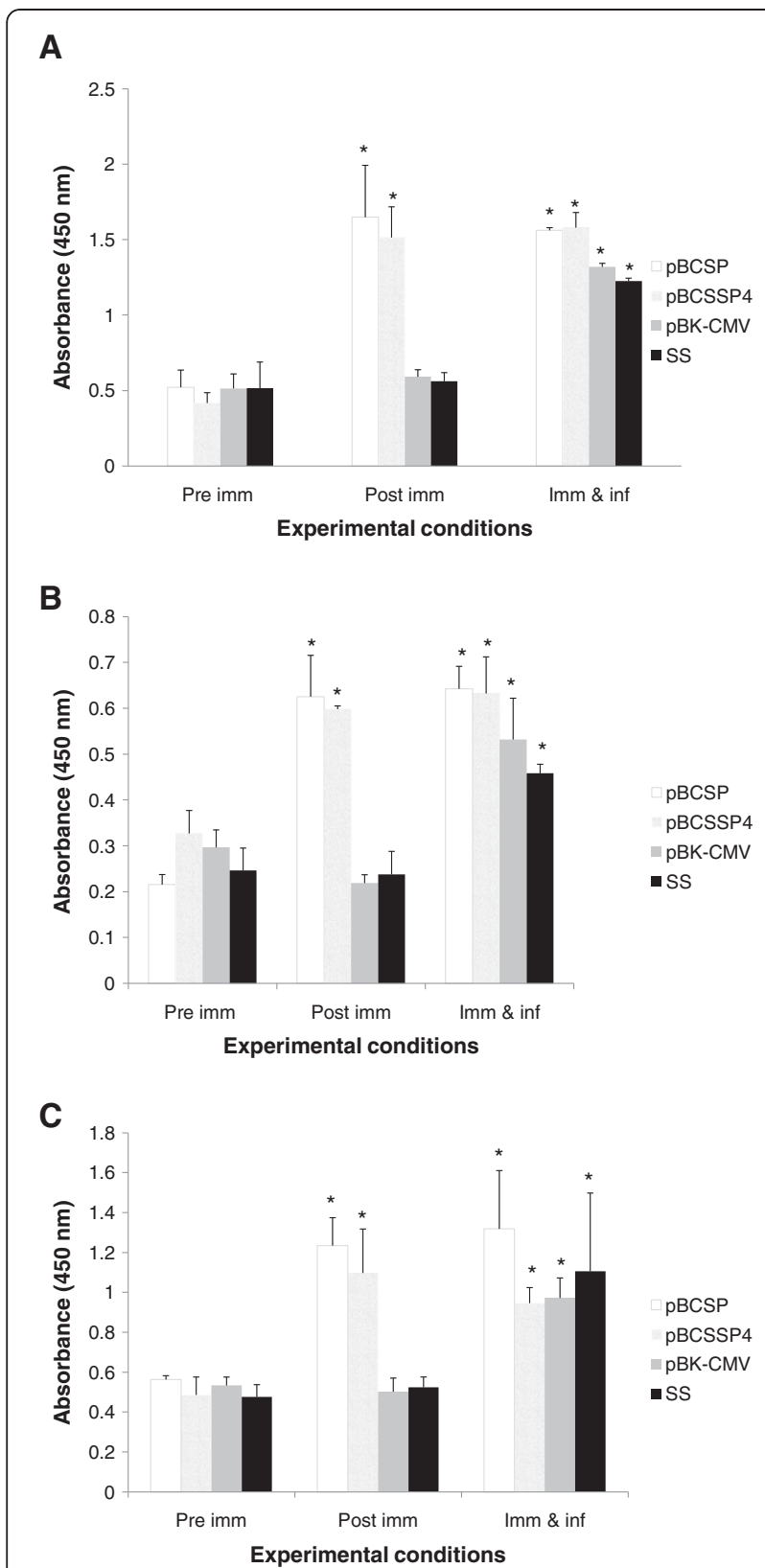

Figure 1 The antibody response to $T$. cruzi infection in immunized dogs. An ELISA was performed to evaluate the serum levels (absorbance in optical density at $405 \mathrm{~nm}$ ) of T. cruzi-specific antibodies at different times. (A) $\lg G$, (B) $\lg G 1$, and (C) $\lg G 2$. To determine all immunoglubulins, $1 \mathrm{\mu g} / \mu \mathrm{L}$ of total T. cruzi extract was used, and the anti-dog lgG, IgG1 and lgG2 antibodies (Novus Biologicals) were diluted 1: 10000 (lgG), 1:5000 (lgG1) and 1:30 000 (lgG2) in blocking buffer. Pre imm: before the immunization, Post imm: 15 days after the last immunization, and Imm \& inf: 60 days after the infection in immunized dogs. The values represent the average of triplicate assays \pm S.D $(* P<0.05)$.

\section{Lymphoproliferative response}

To evaluate the specific cellular immune response in the dogs immunized intramuscularly with the genes from T. cruzi (the dogs were not infected), we studied the lymphoproliferative response to the parasite antigens.

Con A was used as a positive control; since in the presence of a nonspecific mitogen, the cells necessarily proliferate if they are viable.

Positive lymphoproliferative responses were observed in the animals immunized with the T. cruzi genes. The highest lymphocyte S.I. (3.99) was observed in the dogs immunized with the pBCSP plasmid, and although there was less proliferation in the splenocytes from the dogs immunized with pBCSSP4, the S.I. (2.6) was positive (Figure 4), showing a value above 2.0 when the lymphocyte cultures were stimulated with the parasite antigens. In the other groups (controls) there was no cell proliferation; the S. I. values were below 2.0. The cultures stimulated with Con A showed a mean S. I. value of $5.99 \pm 2.05$ demonstrating the cell viability in all experimental groups. These results suggest that the administration of nucleic acids from $T$. cruzi induces the specific stimulation of the cellular immune response.

\section{Discussion}

In animal models, it has been shown that DNA immunization induces and modulates the immune response necessary for the prevention of infectious diseases [18], for the treatment of neoplastic disorders [19] and for allergic treatment [20] and autoimmune diseases [21]. Therefore, we employed this method of immunization to induce a specific immune response against T. cruzi in Beagle dogs.

Antibodies may contribute to the immunity against $T$. cruzi through complement-dependent cytolysis, opsonic and/or cytophilic antibodies that enhance phagocytosis in antibody-dependent cellular lysis reactions against the parasite, and possibly by interfering with the physiologic processes of the parasite. Generally, polyclonal B cell activation that leads to hypergammaglobulinemia and a delayed specific humoral immune response is accepted as a characteristic of acute phase Chagas disease in humans and is reported in rodent experimental models of T. cruzi infection [22,23]. Different IgG isotypes have been implicated in polyclonal B cell activation and parasitic-specific antibody responses; the major antibody isotypes involved in the elimination of parasite blood forms and in decreasing mortality rates are IgG1 and IgG2 [24,25].

The analysis of the IgG subclasses produced by the immunization of canines with both recombinant plasmids revealed that the dominant antibody produced was IgG2; in a previous study in mice immunized with the pBCSP plasmid, the dominant subclass was also IgG2a [26]. These results are consistent with other studies using DNA vaccines; for example, the majority of antibodies produced were of the IgG2 subclass following immunization of dogs with a multi-component DNA vaccine containing $T$. cruzi trans-sialidase family genes 


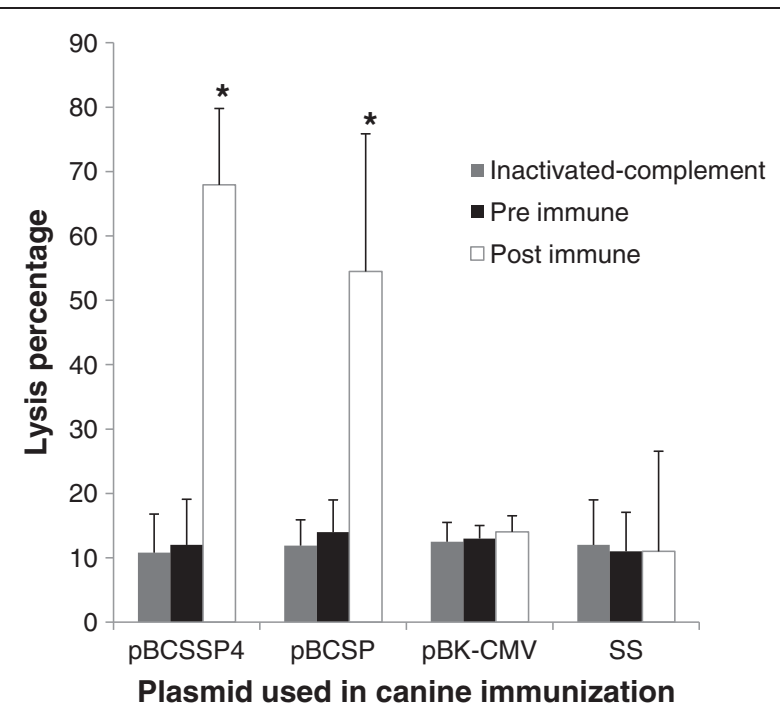

Figure 2 Percentage of complement-mediated lysis of trypomastigotes. Percent killing $=100-[$ (number of parasites after incubation with guinea pig complement/number of parasites after treatment with heat-inactivated complement) $\times 100]$. Inactivatedcomplement: test serum (post immune obtained 15 days after the last immunization) and heat-inactivated complement $\left(56^{\circ} \mathrm{C}\right.$ for $\left.30 \mathrm{~min}\right)$, Pre immune: sample obtained before the immunization and complement, and Post immune: test serum (obtained 15 days after the last immunization) and complement. All dogs were non-infected. The values represent the average of triplicate assays \pm S.D $(* P<0.05)$.
[27]. In addition, in a study performed by PereiraChioccola et al., mice were immunized with a plasmid containing the trans-sialidase gene, and the majority of the antibodies produced were of the IgG2a subclass, whereas following immunization with the recombinant protein, the dominant antibody subclass was IgG1 [28]. Because the subclass profile of antibodies reflects the type of activated helper T cells [29], the predominant IgG2 subclass production after plasmid vaccination with both genes in this study suggests a Th1 skewed response.

Various antibodies against Trypanosoma cruzi elicited by an active infection may have different functional activities. Antibodies that bind to live trypomastigote forms and lyse them in conjunction with complement in an in vitro reaction have been linked to active infection. These lytic antibodies, detected by the complementmediated lysis test, are produced after infection, and have been used to evaluate treatment efficacy in Chagas' disease in which the negative result of the complementmediated lysis test has been interpreted as the absence of parasitemia and a cure. The Zulantay et al. results support the idea of the role of lytic antibodies in the control of parasitemia [30]. Lytic antibodies are not easy to elicit by immunization with dead parasite or with purified T. cruzi antigens, although they are readily detected in mice, rats, rabbits and humans infected with the parasite [31]. The present study indicates that immunization with pBCSP and pBCSSP4 plasmids induced the humoral immune response and that such antibodies mediated the lysis of parasites through the complement system. It has been previously reported that

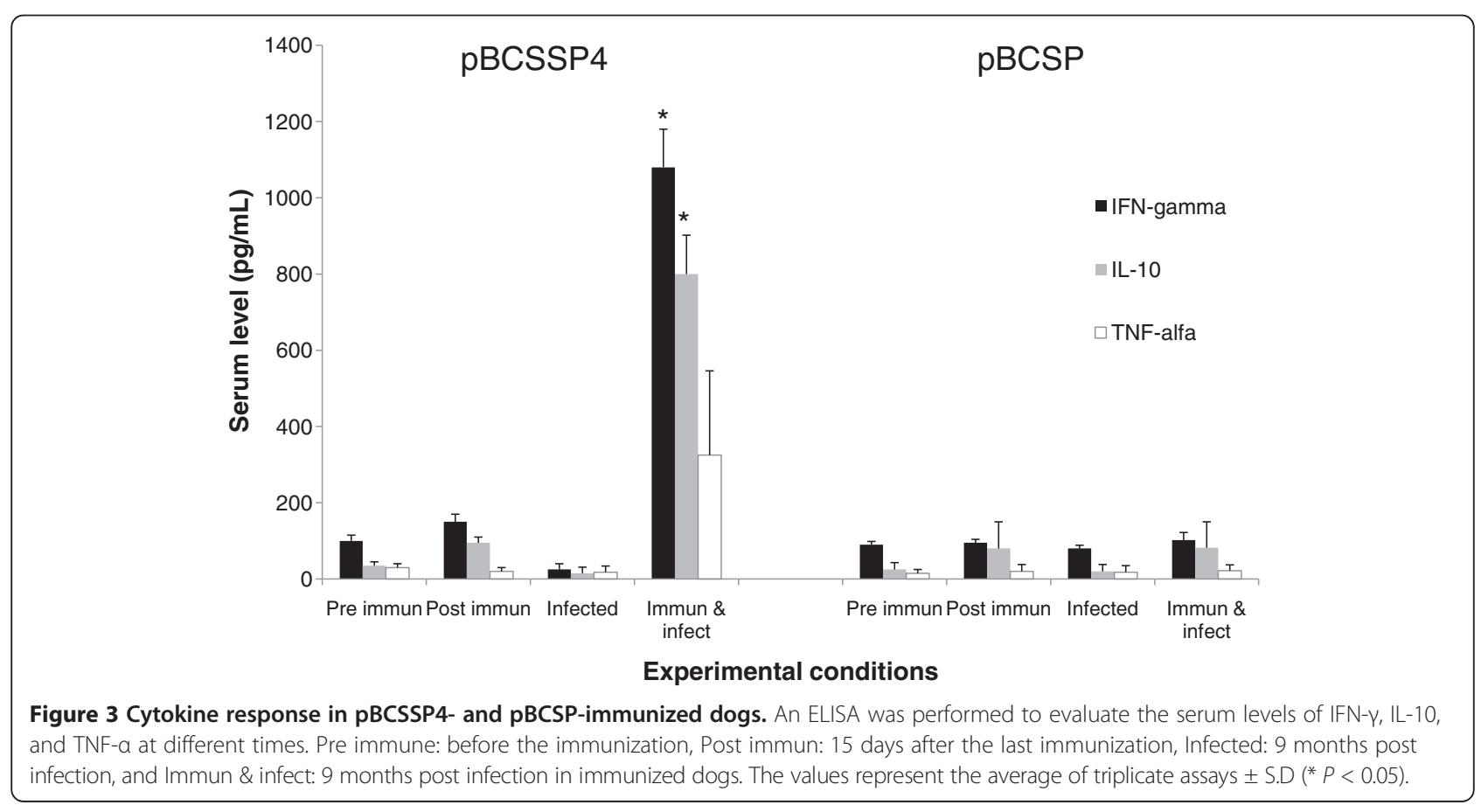




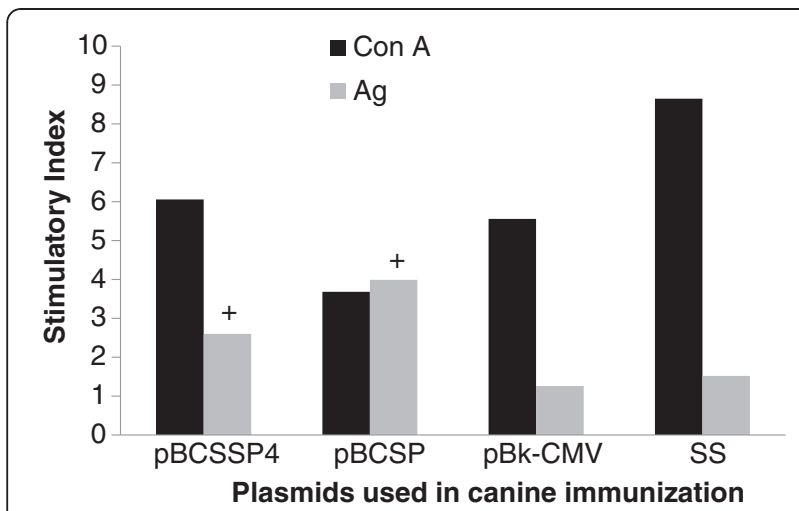

Figure 4 Spleen lymphocyte proliferation in immunized dogs. The values represent the S.I. estimated as follows: mean counts per minute of stimulated cultures/mean counts per minute of nonstimulated cultures. S.I. values equal to or above 2.0 were considered positive (+). Con A: concanavalin A and Ag: parasite total protein extract of epimastigote forms.

complement-mediated lytic antibodies are associated with protection. Our data are comparable to results reported by Sepúlveda et al. showing that the immunization of mice with DNA encoding a regulatory protein of the complement pathway of $T$. cruzi, protected against lethal challenge in a process that involved lytic antibodies [15]. It has been shown that the susceptibility of $T$. cruzi to lysis by complement varies according to the strain [32]; complement lysis assays showed that the Colombian T. cruzi strain is more susceptible to lysis than the Y T. cruzi strain at all serum concentrations [33]. Indeed, even within the same strain, variations in susceptibility have been observed among different clones [34]. There are no reports of $T$. cruzi lysis by complement with Ninoa strain; in our study the results showed a high percentage of lysis, similar to other Mexican Trypanosoma cruzi isolates reported by other authors [32].

The vaccination regimen used in our experimental model induced a cell-mediated immunity characterized by lymphoproliferation, as well as the enhanced production of IFN- $\gamma$, which was in agreement with the results from Cazorla et al. who studied mice immunized with a T. cruzi recombinant cruzipain $(\mathrm{rCz})$; they measured the abundance of $\mathrm{rCz}$-specific IFN- $\gamma$ secreting- CD8+ T-cells in splenocytes depleted of CD4+ lymphocytes, and survival, efficient control of parasite load and restricted inflammatory myopathy were demonstrated [35]. Therefore, our experimental immunization appears promising for the development of a vaccine that generates similar results, since one of our antigens (TcSP) is an enzyme that is expressed in all developmental forms of the parasite (epimastigote, amastigote and trypomastigote) and it is also present at the surface level, characteristics shared with cruzipain.

Previously, immunization with the pBCSSP4 plasmid in a murine model induced significant amounts of IFN $-\gamma$ at 3 hours post immunization, and significant amounts of IL- 6 and TNF- $\alpha$ at 3 and $12 \mathrm{~h}$ post immunization [10]; however, in our canine model, immunization with pBCSSP4 or pBCSP did not induce cytokine production at $12 \mathrm{~h}$ post immunization. At 9 months after infection with $T$. cruzi in the dogs previously vaccinated with the pBCSSP4 plasmid, high levels of IFN- $\gamma(1080 \mathrm{pg} / \mathrm{mL})$ were observed and TNF- $\alpha$ was present to a lesser extent. These results together with the high production of IgG2a subclass indicate a Th1 pattern, and were consistent with reports from Aparicio-Burgos et al.; the circulatory cytokine levels (IFN- $\gamma$ and IL-10) were below the detection limits before and after immunization with a multi-component DNA-prime/DNA-boost vaccine TcVac1- vaccine constituted of antigen-encoding plasmids (pCDNA3.TcG1, pCDNA3.TcG2 and pCDNA3. TcG4) and IL-12- and GMCSF-expression plasmids-, and all the dogs responded to infection with increases in IFN- $\gamma$ levels $(580 \mathrm{pg} / \mathrm{mL}$ approximately at 15 days post infection) [27].

During the testing of a therapeutic DNA vaccine encoding the TSA-1 antigen of T. cruzi in a murine model, the immunized mice exhibited significant increases in $\mathrm{CD} 4$ and $\mathrm{CD} 8 \mathrm{~T}$ cells producing IFN- $\gamma$ during the chronic phase of infection. This increase in IFN- $\gamma$ production was associated with reduced inflammation of the cardiac tissue and a reduction in the parasite load [36]. Moreover, immunization with pELI_Tc2 (DNA from T. cruzi) produced elevated levels of IFN- $\gamma$ that were associated with lower parasite loads after challenge [37]. In accordance with these results, the present study demonstrates that the recombinant plasmid vaccination induced high levels of IFN- $\gamma$, shorter parasitaemia, lower parasite load and also cardiac and clinical protection in immunized/infected dogs, the latter recently reported by Rodríguez-Morales et al. [11].

In dogs at the late stage of infection with T. cruzi characterized by the absence of heart damage, high levels of IL-10 in the serum and supernatants of peripheral blood mononuclear cells have been observed [7]. The significant increase in IFN- $\gamma$ and IL-10 in the group immunized with the pBCSSP4 plasmid is attributed to the TcSSP4 gene, or to the combination of this gene and the presence of the parasite (or the parasite antigenic molecules). The increase in IFN- $\gamma$ and IL-10 cannot be due to the infection alone because an increase in the synthesis of the cytokines was not observed in the other infected groups. Therefore, immunization modulates the pattern of cytokine expression in infected dogs.

The results presented in this study support DNA immunization as a strategy for designing anti-T. cruzi vaccines. It was demonstrated that this type of vaccine effectively induces antigen-specific antibodies and produces a Th1-type cellular immune response reflected in 
a moderate cardiac and clinical protection against Chagas disease because this strategy 1) avoided acute phase fever, 2) induced an immune response that manifested as lymph node enlargement as part of hostprotective activity, 3) avoided heart rate increases during the acute and/or chronic stages, and 4) most interestingly, halted the symptomatic progression to severe heart conduction abnormalities [11].

These vaccines will allow us to determine if this immune response confers protection against acute and chronic $T$. cruzi infection, the course of the infection, the pathological variables, and the clinical status in Beagle dogs with experimentally induced trypanosomiasis.

\section{Abbreviations \\ O.D: Optical density; rTCSSP4: Recombinant protein TCSSP4; TCSSP4: Gene encoding an amastigote-specific surface protein in T. cruzi; IFN-Y: Interferon- gamma; TCSP: Gene encoding a member of the trans-sialidase family in $T$. cruzi; pBk-CMV: Commercial empty plasmid used as a cloning vector; pBCSP: Plasmid containing the TCSP gene; PBCSSP4: Plasmid containing the TCSSP4 gene; ELISA: Enzyme-linked immunosorbent assay; SS: Saline solution; IIF: Indirect immunofluorescence; PBS: Phosphate buffered saline; IL- 10: Interleukin-10; TNF-a: Tumor necrosis factor-alpha; DMEM: Dulbecco's Modified Eagle Medium; Con A: Concanavalin A; S.I: Stimulatory index; ANOVA: Analysis of variance.}

\section{Competing interests}

The authors declare that they have no competing interests.

\section{Authors' contributions}

MAF and ORM conceived the study, conducted the animal trials, collected and analyzed data, and completed manuscript preparation. MABV, ERAZ and DSF carried out the immunological studies. SCCS carried out the molecular studies. RAA, JLRE and PAR contributed to the concept and design of the study. All authors read and approved the manuscript.

\section{Acknowledgements}

This work was funded by the Consejo Nacional de Ciencia y Tecnología (CONACYT), Mexico, grant No. 69081 FONSEC SSA/IMSS/ISSSTE.

\section{Author details}

'Department of Molecular Biology, Instituto Nacional de Cardiología "Ignacio Chávez", Juan Badiano No. 1, Col. Sección XVI, Tlalpan, CP 14080, Mexico City, Mexico. ${ }^{2}$ Department of Parasitology, Escuela Nacional de Ciencias Biológicas, Instituto Politécnico Nacional, Prolongación de Carpio y Plan de Ayala, Col. Santo Tomás, Miguel Hidalgo, CP 11340, Mexico City, Mexico. ${ }^{3}$ Department of Infectomics and Molecular Pathogenesis, Centro de Investigación y de Estudios Avanzados-IPN, Av. Instituto Politécnico Nacional No. 2508, Col. San Pedro Zacatenco, Gustavo A. Madero, CP 07360, Mexico City, Mexico.

${ }^{4}$ Research Direction, Instituto Nacional de Cardiología "Ignacio Chávez", Juan Badiano No. 1, Col. Sección XVI, Tlalpan, CP 14080, Mexico City, Mexico.

Received: 29 June 2012 Accepted: 7 February 2013

Published: 11 March 2013

\section{References}

1. World Health Organization: Chagas: one hundred years later. Bull World Health Organ 2009, 87:491-492 [http://www.who.int/bulletin/volumes/87/7/ 09-030709/en/index.html].

2. Hoft D, Eickhoff C: Type 1 immunity provides optimal protection against both mucosal and systemic Trypanosoma cruzi challenges. Infect Immun 2002, 70:6715-6725.

3. Maguire J: Control of Chagas disease: report of a WHO expert committee. N Engl J Med 2006, 355:760-761.

4. Tekiel V, Alba-Soto C, González S, Postan M, Sánchez D: Identification of novel vaccine candidates for Chagas disease by immunization with sequential fractions of a trypomastigote cDNA expression library. Vaccine 2009, 27:1323-1332.

5. Ramírez MA: Enfermedad de Chagas en el perro: mitos y realidades. Revista AMMVEPE 2006, 17:213-216 (in Spanish).

6. Turriago G, Vallejo G, Guhl F: Seroprevalencia de Trypanosoma cruzi en perros de dos áreas endémicas de Colombia. Revista Med 2008, 16:11-18 (in Spanish).

7. Guedes PM, Veloso VM, Afonso LC, Caliari MV, Carneiro CM, Diniz LF, Marques-da-Silva EA, Caldas IS, Do Valle Matta MA, Souza SM, Lana M, Chiari E, Galvão LM, Bahia MT: Development of chronic cardiomyopathy in canine Chagas disease correlates with high IFN- - , TNF- $a$, and low IL-10 production during the acute infection phase. Vet Immunol Immunopathol 2009, 130:43-52.

8. Reed SG: Cytokine control of macrophage parasites Leishmania and Trypanosoma cruzi. In Molecular Approaches to Parasitology. New York: Weily Liss; 1995:443-453.

9. Silva JS, Vespa GNR, Cardoso MAG, Alberti JCS, Cunha FQ: Tumor necrosis factor alpha mediates resistance to Trypanosoma cruzi infection in mice by inducing nitric oxide production in infected gamma interferonactivated macrophages. Infect Immun 1995, 63:4862-4867.

10. Arce-Fonseca M, Ramos-Ligonio A, López-Monteón A, Salgado-Jiménez B, Talamás-Rohana P, Rosales-Encina JL: A DNA vaccine encoding for TcSSP4 induces protection against acute and chronic infection in experimental Chagas disease. Int J Biol Sci 2011, 7:1230-1238.

11. Rodríguez-Morales O, Pérez-Leyva MM, Ballinas-Verdugo MA, CarrilloSánchez SC, Rosales-Encina JL, Alejandre-Aguilar R, Reyes PA, Arce Fonseca M: Plasmid DNA immunization with Trypanosoma cruzi genes induces cardiac and clinical protection against Chagas disease in the canine model. Vet Res 2012, 43:79.

12. Norma Oficial Mexicana NOM-0062-ZOO-1999: Especificaciones Técnicas para el Cuidado y Uso de Animales de Laboratorio. Mexico City: Diario Oficial de la Federación; 1999.

13. Monteón VM, Furuzawa-Carballeda J, Alejandre-Aguilar R, Aranda-Fraustro A, Rosales-Encina JL, Reyes PA: American Trypanosomosis: In situ and generalized features of parasitism and inflammation kinetics in a murine model. Exp Parasitol 1996, 83:267-274.

14. Rodríguez-Morales O, Ballinas-Verdugo MA, Alejandre Aguilar R, Reyes PA, Arce Fonseca M: Trypanosoma cruzi connatal transmission in dogs with Chagas disease: Experimental case report. Vector Borne Zoonotic Dis 2011, 11:1365-1370.

15. Sepúlveda P, Hontebeyrie M, Liegeard P, Mascilli A: DNA-based immunization with Trypanosoma cruzi complement regulatory protein elicits complement lytic antibodies and confers protection against Trypanosoma cruzi infection. Infect Immun 2000, 6:4986-4991.

16. Fossum TW: Small Animal Surgery. St. Louis: MOSBY ELSEVIER; 2007.

17. Vidal T, Hidalgo C, Alberti E, Padilla M, López R, Sarmiento ME, Leyva JL, Fariñas $M$, Acosta A: Respuesta linfoproliferativa frente a proteínas de la vacuna cubana antimeningoccócica en ratones Balb/c inmunizados con una librería genómica de expresión. VacciMonitor 1996, 3:8-10 (in Spanish).

18. Amara RR, Villinger F, Altman JD, Lydy SL, O'Neil SP, Staprans SI, Montefiori DC, Xu Y, Herndon JG, Wyatt LS, Candido MA, Kozyr NL, Earl PL, Smith JM, Ma HL, Grimm BD, Hulsey ML, Miller J, McClure HM, McNicholl JM, Moss B, Robinson $\mathrm{HL}$ : Control of a mucosal challenge and prevention of AIDS by a multiprotein DNA/MVA Vaccine. Science 2001, 292:69-74.

19. Riemer AB, Kurz H, Klinger M, Scheiner O, Zielinski CC, Jensen-Jarolim E: Vaccination with cetuximab mimotopes and biological properties of induced anti-epidermalgrowth factor receptor antibodies. J Natl Cancer Inst 2005, 97:1663-1670.

20. Broide DH, Stachnick G, Castaneda D, Nayar J, Miller M, Cho JY, Roman M, Zubeldia J, Hayashi T, Raz E: Systemic administration of immunostimulatory DNA sequences mediates reversible inhibition of Th2 responses in a mouse model of asthma. J Clin Immunol 2001, 21:175-182.

21. Wisman A, Ruiz P, Hirschberg D, Gelman A, Oksenberg J, Brocke S, Mor F, Cohen IR, Steinman L: Suppressive vaccination with DNA encoding a variable region gene of the T-cell receptor prevents autoimmune encephalomyelitis and acivates Th2 immunity. Nat Med 1996, 2:899-905.

22. Kumar $\mathrm{S}$, Tarleton RL: The relative contribution of antibody production and CD8+ T cell function to immune control of Trypanosoma cruzi. Parasite Immunol 1998, 20:207-216.

23. Kuhn RE: Immunology of Trypanosoma cruzi infections. In Parasitic Diseases. Edited by Mansfield JM. New York: Marcel Dekker; 1981:137-166. 
24. Coura-Vital W, Carneiro CM, Martins HR, de Lana M, Veloso VM, Teixeira-Carvalho A, Bahia MT, Corrêa-Oliveira R, Martins-Filho OA, Tafuri WL, Reis AB: Trypanosoma cruzi: immunoglobulin isotype profiles during the acute phase of canine experimental infection with metacyclic or blood trypomastigotes. Exp Parasitol 2008, 120:269-74.

25. Guedes PM, Veloso VM, Gollob KJ, Afonso LC, Caldas IS, Vianna P, de Lana M, Chiari E, Bahia MT, Galvão LM: IgG isotype profile is correlated with cardiomegaly in Beagle dogs infected with distinct Trypanosoma cruzi strains. Vet Immunol Immunopathol 2008, 124:163-168.

26. Salgado-Jiménez B, Arce-Fonseca M, Baylón-Pacheco L, Talamás-Rohana P, Rosales-Encina JL: Differential immune response in mice immunized with either the A, R, or C domains from TCSP protein of Trypanosoma cruzi or with the coding DNAs. Parasite Immunol 2013, 35:32-41.

27. Aparicio-Burgos JE, Ochoa-García L, Zepeda-Escobar JA, Gupta S, Dhiman M, Martínez JS, de Oca-Jiménez RM, Val Arreola M, Barbabosa-Pliego A, Vázquez-Chagoyán JC, Garg NJ: Testing the efficacy of a multi-component DNA-prime/DNA-boost vaccine against Trypanosoma cruzi infection in dogs. PLoS Negl Trop Dis 2011, 5:e1050.

28. Pereira-Chioccola VL, Costa F, Ribeirao M, Soares IS, Arena F, Schenkman S, Rodrigues MM: Comparison of antibody and protective immune responses against Trypanosoma cruzi infection elicited by immunization with a parasite antigen delivered as naked DNA or recombinant protein. Parasite Immunol 1999, 21:103-110.

29. Mosmann TR, Sad S: The expanding universe of T -cell subsets: Th1, Th2 and more. Immunol Today 1996, 17:138-146.

30. Zulantay I, Venegas J, Apt W, Solari A, Sanchez G: Lytic antibodies in Trypanosoma cruzi-infected persons with low parasitemia. Am J Trop Med Hyg 1998, 58:775-779.

31. Krautz GM, Kissinger JC, Krettli AU: The targets of the lytic antibody response against Trypanosoma cruzi. Parasitol Today 2000, 16:31-34.

32. León-Pérez F, Gómez-Garcia L, Alejandre-Aguilar R, López R, Monteón VM: Mexican Trypanosoma cruzi isolates: in vitro susceptibility of epimastigotes to anti-trypanosoma cruzi drugs and metacyclic forms to complement-mediated lysis. Vector Borne Zoonotic Dis 2007, 7:330-336.

33. Cestari Idos S, Evans-Osses I, Freitas JC, Inal JM, Ramirez MI: Complement C2 receptor inhibitor trispanning confers an increased ability to resist complement-mediated lysis in Trypanosoma cruzi. J Infec Dis 2008 198:1276-1283.

34. Braga EM, Galvão LMC, Chiari E, Martins MS: Difference in susceptibility to lysis between clones of the $\mathrm{Y}$ strain of Trypanosoma cruzi. Mem Inst Oswaldo Cruz 1993, 88:529-534.

35. Cazorla SI, Frank FM, Becker PD, Corral RS, Guzmán CA, Malchiodi EL: Prime-boost immunization with cruzipain co-administered with MALP-2 triggers a protective immune response able to decrease parasite burden and tissue injury in an experimental Trypanosoma cruzi infection model. Vaccine 2008, 26:1999-2009.

36. Zapata-Estrella H, Hummel-Newell C, Sanchez-Burgos G, Escobedo-Ortegon J, Ramirez-Sierra MJ, Arjona-Torres A: Control of Trypanosoma cruzi infection and changes in T-cell populations induced by a therapeutic DNA vaccine in mice. Immunol Lett 2006, 103:186-191.

37. Tekiel V, Alba-Soto CD, González Cappa SM, Postan M, Sánchez DO: Identification of novel vaccine candidates for Chagas' disease by immunization with sequential fractions of a trypomastigote CDNA expression library. Vaccine 2009, 27:1323-1332.

doi:10.1186/1297-9716-44-15

Cite this article as: Arce-Fonseca et al.: Specific humoral and cellular immunity induced by Trypanosoma cruzi DNA immunization in a canine model. Veterinary Research 2013 44:15.

\section{Submit your next manuscript to BioMed Central and take full advantage of:}

- Convenient online submission

- Thorough peer review

- No space constraints or color figure charges

- Immediate publication on acceptance

- Inclusion in PubMed, CAS, Scopus and Google Scholar

- Research which is freely available for redistribution

Submit your manuscript at www.biomedcentral.com/submit
C Biomed Central 